\title{
Estrategias didácticas empleadas desde la presencialidad remota en la División de Educación para el Trabajo de la Universidad Nacional en tiempos de pandemia
}
Didactic strategies used in remote presence at Universidad Nacional's Education for Work Division during pandemic times
Estratégias de ensino utilizadas a partir de locais remotos na Divisão de
Educação para o Trabalho da Universidade Nacional em tempos de pandemia

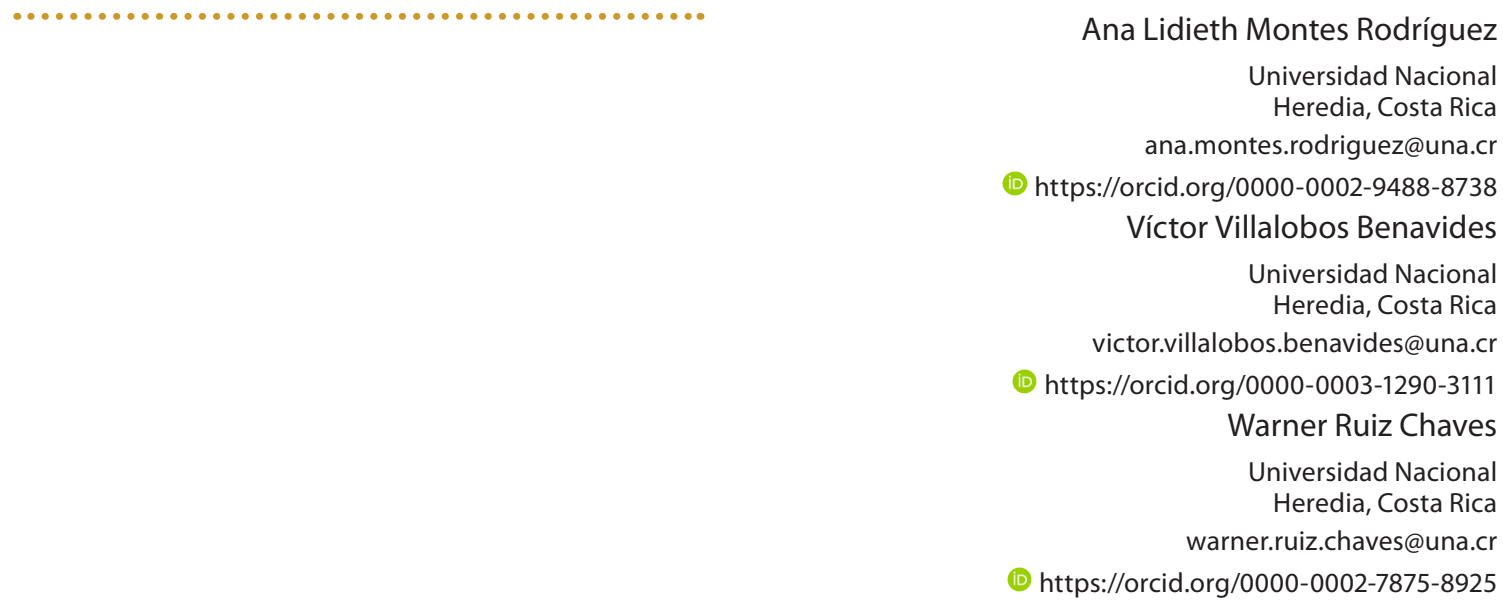

Recibido - Received - Recebido: 03 / 08 / 2020 Corregido - Revised-Revisado: 13 / 09 / 2020 Aceptado - Accepted - Aprovado: 25 / 09 / 2020

DOl: https://doi.org/10.22458/ie.v22iEspecial.3251

URL: https://revistas.uned.ac.cr/index.php/innovaciones/article/view/3251

\begin{abstract}
Resumen: El artículo presenta las estrategias didácticas utilizadas en la División de Educación para el Trabajo (DET) de la Universidad Nacional (UNA), Costa Rica para la implementación de la presencialidad remota como respuesta a los cambios en los procesos educativos producidos por el virus responsable de la COVID-19; para concretar lo anterior se contó con la participación del personal docente y el estudiantado de la unidad académica antes citada durante el primer ciclo y la primera parte del segundo ciclo del año 2020, mediante un estudio de tipo cuantitativo con una muestra no probabilística de participantes voluntarios a través de la técnica de encuesta. Se determinó que las estrategias puestas en práctica por parte de los docentes fueron oportunas para producir el efecto deseado (el aprendizaje desde la presencialidad remota) en el contexto vivido, dado que se diversificaron las propuestas didácticas hacia el estudiantado y la percepción de este fue que se lograron concretar los objetivos de aprendizaje de las distintas asignaturas del Bachillerato y Licenciatura en Orientación, además permitió un uso intensivo de recursos tecnológicos para mediar los aprendizajes. Por último, el estudio demostró la necesidad de clarificar la conceptualización de aprendizaje remoto en el personal académico, además de ahondar en futuros procesos investigativos que permitan reflexionar otros elementos propios de esta modalidad, como su pertinencia curricular, de acceso tecnológico y pedagógica.
\end{abstract}

Palabras clave: Estrategias educativas, Aprendizaje, Enseñanza superior, Docencia, Presencialidad remota, Estrategias didácticas, COVID-19 


\begin{abstract}
The article presents the didactic strategies used in the Division of Education for Work (DET) of Universidad Nacional (UNA) in Costa Rica to implement remote presence as a response to the changes in the educational processes produced by the virus responsible for COVID-19. To specify the above, the teaching staff and students of the aforementioned Academic Unit participated during the first cycle and the first part of the second cycle of 2020, through a quantitative study with a non-probabilistic sample of voluntary participants through the survey technique. It was determined that the strategies put into practice by the teachers were opportune to produce the desired effect (learning from remote presence) in the lived context, given that the didactic proposals were diversified towards the student body and the perception of this was that. The learning objectives of the different subjects of the Baccalaureate and Bachelor's Degree in Guidance were achieved, and it also allowed an intensive use of technological resources to mediate learning. Finally, the study demonstrated the need to clarify the conceptualization of remote learning in academic staff, in addition to delving into future research processes that allow reflection on other elements of this modality, such as its curricular relevance, technological and pedagogical access.
\end{abstract}

Key Words: Educational strategies, learning, teaching, higher education, didactic strategies, remote presence, COVID-19

Resumo: $\mathrm{O}$ artigo apresenta as estratégias didáticas utilizadas na Divisão de Educação para o Trabalho (DET) da Universidade Nacional (UNA) da Costa Rica para a implementação do atendimento à distância como resposta às mudanças nos processos educacionais produzidos pelo vírus responsável pela COVID-19; para isso tivemos a participação de professores e alunos da Unidade Acadêmica participaram durante o primeiro ciclo e a primeira parte do segundo ciclo de 2020, através de um estudo quantitativo com uma amostra não probabilística de participantes voluntarios, através da técnica de pesquisa.

Constatou-se que as estratégias postas em prática pelos professores foram oportunas para produzir o efeito desejado (aprender com a presença remota) no contexto vivido, visto que as propostas didáticas se diversificaram em direção ao corpo discente e a percepção deste foi que Os objetivos de aprendizagem das diferentes disciplinas do Bacharelado e do Bacharelado em Orientação foram alcançados, permitindo também o uso intensivo de recursos tecnológicos para mediar a aprendizagem. Finalmente, o estudo demonstrou a necessidade de esclarecer a conceituação da aprendizagem a distância em docentes, além de aprofundar futuros processos de pesquisa que permitam refletir sobre outros elementos dessa modalidade, como sua relevância curricular, acesso tecnológico e pedagógico.

Palavras-chave: Estratégias educacionais, aprendizagem, ensino, ensino superior, docência, estratégias didáticas, presença remota, COVID-19

\title{
INTRODUCCIÓN
}

Las instituciones educativas, a nivel mundial, han visto una serie de cambios importantes durante el año 2020 debido a la pandemia producida por el virus responsable de la COVID-19 (OMS, 2020). En el caso de Costa Rica y específicamente de la Universidad Nacional (UNA), en términos generales, se modificó el accionar académico para transitar de un modelo presencial a otro denominado "presencialidad remota", por tanto, desde la División de Educación para el Trabajo (DET), unidad académica adscrita al Centro de Investigación y Docencia en Educación (CIDE) de la UNA, se propuso como objetivo general determinar las estrategias didácticas implementadas por el personal docente y estudiantado desde la presencialidad remota en la División de Educación para el Trabajo en tiempos de pandemia.

En atención a lo descrito, se tiene como antecedentes, dado el contexto provocado por la pandemia, que las instituciones educativas a nivel mundial llevaron sus actividades mediante la educación remota, en la cual se mezcló la educación presencial tradicional y el uso de tecnología digital. Al respecto, Tijo (2020) afirma que "lo que es sin precedentes es que una crisis de esta magnitud hubiera ocurrido a nivel mundial y hubiera forzado al $90 \%$ de los estudiantes de colegios y universidades a acceder a alguna forma de educación de forma remota" (p. 3); no obstante, la Universidad Nacional, tiempo atrás, ha trabajado en el fortalecimiento de los recursos tecnológicos en los procesos de aprendizaje.

En este sentido, Castro (2012), indica que la UNA ha desarrollado iniciativas de innovación académica desde el año 1999, con la implementación de la Maestría virtual en Desarrollo Rural, asimismo, como una estrategia organizada y planificada de innovación académica con las tecnologías de información 
y comunicación, en el 2006 se realizó un diagnóstico acerca del uso de las tecnologías digitales en la docencia, entre las cuales se destacan las tecnologías digitales como apoyos a las clases presenciales, páginas web docentes para colocar material del curso y uso de aplicaciones para el uso de foros, chats, entre otros o para uso en la bimodalidad (combinación presencialidad y virtualidad).

Aunado a lo anterior, en el año 2005 se implementó desde la plataforma Moodle, el aula virtual, como un recurso para la docencia (Castro y otros, 2014). En la actualidad se cuenta con cuatro modalidades de aula virtual: institucional, educación permanente, actualización y la de investigación y desarrollo. Además, en el año 2018, la UNA realizó un esfuerzo importante para la entrega a la comunidad educativa de licencias de la plataforma Microsoft Office $365^{\circledR}$, compuesto por un paquete útil de aplicaciones para la docencia y en el 2019 se entrega una licencia de la aplicación de videoconferencias Zoom ${ }^{\circledast}$ a las Unidades Académicas. Es importante mencionar, que, desde la Unidad Académica, el personal docente de la carrera de Administración Educativa se capacitó durante el año 2019, en el uso de herramientas para la mediación docente bajo la bimodalidad, a partir del rediseño del plan de estudio, implementado este año.

Tal como se indicó, la UNA ha realizado esfuerzos importantes para incorporar herramientas tecnológicas como apoyo a la entrega de la docencia, sin embargo, a partir de la situación provocada por el virus responsable de la COVID-19, surgen nuevos desafíos que presentan diversos escenarios o posibilidades para las instituciones de educación superior, entre éstas, el uso de medios tecnológicos para continuar con el servicio educativo, no obstante, esto implicó reinventarse en poco tiempo, transformando prácticas que hasta ahora eran presenciales, en el caso de la UNA, hacia lo que el Consejo Académico (CONSACA) ha denominado la presencialidad remota (CONSACA, 2020).

A nivel latinoamericano, otros países han buscado posibilidades que ya tenían para brindar la continuidad requerida al estudiantado, por ejemplo, según UNESCO (2020), "Argentina y Uruguay, donde la vigencia de políticas digitales de larga trayectoria, como son "Educ.ar" y "Plan Ceibal", facilitaron la logística para continuar con las clases a distancia" (párr. 18) y otros como "Bolivia, Chile, Guatemala, Hondura s, Panamá, República Dominicana y Colombia hicieron un gran esfuerzo en poner en línea nuevas plataformas virtuales para continuar las clases con modalidad a distancia" (párr. 19); destaca en ese esfuerzo Perú con una doble oferta tecnológica y tradicional; Brasil con el programa "Tiempo de aprender" (para alfabetización por televisión) y en Argentina el Plan federal "Juan Manso" (conectividad, equipamiento, una propuesta de formación y capacitación docente y una plataforma de navegación gratuita), entre otros (UNESCO, 2020). Nótese entonces que la respuesta, en la mayoría de los países latinoamericanos, ha resultado en una combinación del uso de recursos tecnológicos digitales y elementos de la presencialidad tradicional.

Por otro lado, a nivel de referentes conceptuales, este manuscrito aborda la noción de presencialidad remota y de estrategias didácticas como conceptos claves a lo largo del documento; en relación con el primero de ellos, se debe señalar que para Hodges, Moore, Lockee, Trust y Bond (2020) el término de presencialidad remota hace referencia a la "Emergency Remote Teaching", la cual se da en contextos donde la educación no puede ser presencial o híbrida por una situación de emergencia o crisis, pero que una vez finalizada esa situación se vuelve al antiguo formato, por lo que se asume de manera temporal el uso de tecnología multimedial o audiovisual, sin llegar a ser aprendizaje en línea (párr. 13). Para Tijo (2020)

La Enseñanza Remota de Emergencia (ERE) ha surgido como una definición acuñada por expertos en educación para establecer una diferenciación entre la educación asistida como respuesta inmediata a una situación de emergencia en contraste con una educación virtual de alta calidad. Un curso de educación virtual de alta calidad a nivel universitario requiere entre 6 a 8 meses de preparación. En contraste, la ERE fue una respuesta en la cual se contó con un tiempo de iniciación no mayor a una semana y en el cual se fueron haciendo ajustes sobre la marcha a medida que se iba avanzando en los contenidos de las asignaturas. (p. 3) 
Desde esta perspectiva, la conceptualización que proponen Hodges, Moore, Lockee, Trust y Bond (2020) y Tijo (2020) evidencia que la "enseñanza remota de emergencia" es una opción que permite la flexibilidad en los procesos de aprendizaje pues, precisamente por la necesidad de hacer los ajustes pedagógicos y tecnológicos en corto tiempo, se realizan modificaciones para dar continuidad a los procesos educativos en donde el personal docente y el estudiantado, desde sus hogares y apoyados por tecnología digital, concretan el hecho educativo. Es así como la presencialidad remota, en tiempos de pandemia, se posiciona como una opción viable a la cual recurrieron muchas instituciones de educación superior (Alexander, 2020), entre ellas, la Universidad Nacional de Costa Rica.

En consonancia con lo antes expuesto, la Vicerrectoría de Docencia (2020a) de la Universidad Nacional señala que

no considera este proceso, como una virtualización de la oferta presencial ni un cambio de modalidad, sino más bien una transición de la presencialidad a procesos de enseñanza y aprendizaje de acceso remoto con apoyo tecnológico mientras dure la emergencia nacional por el Covid-19 y tomando en cuenta recursos y herramientas accesibles a la población estudiantil. (p. 2)

De acuerdo con lo descrito, la UNA presenta esta opción como una entrega de la docencia alternativa por la situación que se vive, sin que implique cambios estructurales y/o de modalidad en la oferta que brinda la Universidad. Al respecto señalan Hodges, Moore, Lockee, Trust y Bond (2020) que "el objetivo principal no es recrear un ecosistema educativo sólido, sino, proporcionar acceso temporal a la instrucción y los apoyos educativos de una manera que sea rápida de configurar y esté disponible de manera confiable durante una emergencia" (párr. 14).

En el caso de la DET, asumió una noción de presencialidad remota similar a la propuesta por el llinois State Board of Education (2020) en donde se hace un énfasis en mantener comunicado al personal docente con el estudiantado para que el proceso de aprendizaje se logre concretar y esa transición no sea barrera para generar desigualdades; para ello se implementó una estrategia basada en el uso de recursos tecnológicos en línea, no solo porque respondía a las posibilidades, sino porque ya es parte del quehacer del estudiante, según lo demuestra la "Encuesta posibilidades de uso de tecnologías del estudiantado" cuando señala que los estudiantes de la DET utilizan herramientas tecnológicas para sus cursos académicos en un 66,7\% (Vicerrectoría de Docencia, 2020b). En este sentido, para efectos de este estudio, la estrategia se entiende de acuerdo con lo planteado por Díaz-Barriga y Hernández (2005),

las estrategias son procedimientos que el agente de enseñanza utiliza en forma reflexiva y flexible para promover el logro de aprendizajes significativos en los alumnos y enlazándolo con lo antes dicho, las estrategias de enseñanza son medios o recursos para prestar la ayuda pedagógica. (p. 139)

Precisamente por lo descrito, desde el segundo concepto clave de este manuscrito, la estrategia, es importante señalar que debe tener una intencionalidad clara en un contexto específico, considerando que debe ser adaptable de parte de quien enseña, pero también modificable por quien aprende, de modo que se logre lo propuesto en el proceso de enseñanza y aprendizaje. De este modo, las estrategias didácticas hacen referencia a los procedimientos utilizados por la persona docente para promover aprendizaje (s) en el estudiantado, sin importar el contexto donde se utilicen. Dichas estrategias deben ser seleccionadas de tal forma que contribuyan al tratamiento de los contenidos de manera adecuada para que el aprendizaje significativo se logre.

Por esta razón y en consonancia con Díaz-Barriga y Hernández (2005), las estrategias de aprendizaje y las estrategias de enseñanza son complemento, por lo que en esta investigación no se hizo una diferenciación de estas, dado que se coincide con Colom, Salinas y Sureda (1988), citados por Jiménez y Robles 
(2016) "cuando afirmaron que la estrategia acoge tanto métodos, como medios y técnicas, considerando que el concepto proporciona mayor flexibilidad y utilidad en el proceso didáctico" (p. 108). De este modo, este estudio parte de una definición de estrategia didáctica que es integradora del proceso de enseñanza y aprendizaje y la utilización de recursos y que fue modificada o adaptada para ser realizada desde la presencialidad, en consonancia con lo que propone Federofv (2004) cuando señala que el objetivo de las estrategias es "propiciar procesos interactivos entre los y las estudiantes y sus docentes, o entre los y las estudiantes y sus objetos de conocimiento, que le permitan llegar a una apropiación desde la comprensión de los procesos" (p. 86).

En el anterior sentido, es importante rescatar que para esta investigación se seleccionó la clasificación de estrategias didácticas propuestas por Díaz-Barriga y Hernández (2005) dado que por la naturaleza de esta incide en los procesos cognitivos del estudiantado; se detalla esta clasificación en la tabla 1.

TABLA 1

Clasificación de estrategias didácticas utilizadas en la investigación

Estrategia

Activar o generar conocimientos previos

Orientar y guiar sobre los saberes disciplinares

Mejorar la codificación elaborativa de la información

Organizar la información nueva pro aprender

Promover el enlace entre los conocimientos previos y la nueva información

Composición y aprendizaje de textos

Autoaprendizaje

Aprendizaje interactivo

Aprendizaje colaborativo

\section{Definición}

Dentro de este rubro vamos a incluir a todas aquellas estrategias dirigidas a activar o a generar los conocimientos previos en los aprendices. Al mismo tiempo, tales actividades pueden contribuir a esclarecer las expectativas apropiadas en los alumnos sobre los aprendizajes próximos de información nueva.

Son aquellos recursos que se utilizan para guiar, orientar y ayudar a mantener la atención de los aprendices durante una sesión, discurso o texto. La actividad de guía y orientación es una actividad fundamental para el desarrollo de cualquier acto de aprendizaje. En este sentido, las estrategias de este grupo deben proponerse preferentemente como estrategias de tipo coinstruccional dado que pueden aplicarse de manera continua para indicar a los alumnos en qué conceptos o ideas focalizar los procesos de atención y codificación.

Se trata de estrategias que van dirigidas a proporcionar la oportunidad para que realice una codificación ulterior, complementaria o alternativa a la expuesta por el enseñante o, en su caso, por el texto. Nótese que la intención es conseguir que, con el uso de estas estrategias, la información nueva por aprender se enriquezca en calidad proveyéndole de una mayor contextualización o riqueza elaborativa para que los aprendices la asimilen mejor. Por tal razón, se recomienda que las estrategias también se utilicen en forma coinstruccional.

Proveen de una organización global de las ideas contenidas en la información nueva; proporcionan una organización a la información que se ha de aprender, mejora su significatividad lógica, y, en consecuencia, hace más probable el aprendizaje significativo de los alumnos, promueven "conexiones internas" en las estructuras cognitivas del estudiantado.

Ayudan para crear enlaces adecuados entre los conocimientos previos y la información nueva a aprender, asegurando con ello una mayor significatividad de los aprendizajes logrados; a este proceso de integración entre lo "previo" y lo "nuevo" se le denomina: construcción de "conexiones externas".

Describen cómo se comprende y aprende de manera estratégica la información contenida en los textos académicos que habitualmente los estudiantes de diversos niveles educativos realizan.

Van dirigidas al "aprender a aprender", es decir, que promueven el aprendizaje independiente y autónomo del estudiantado.

Promueven el aprendizaje entre las personas participantes del proceso, por ejemplo, entre el profesorado y el alumnado a través de exposiciones del docente, con preguntas al estudiantado, conferencias de expertos, entrevistas

Se refieren a la construcción conjunta del conocimiento del estudiantado, es decir, el aprendizaje entre pares.

Fuente: Adaptación de Díaz-Barriga y Hernández (2005). 
Por último, se debe señalar que el estudio planteó como objetivos el identificar las estrategias didácticas implementadas por el personal académico de la DET en la presencialidad remota con el fin de continuar con el proceso de aprendizaje; conocer la percepción del estudiantado en relación con las estrategias didácticas implementadas para la atención de la presencialidad remota durante la pandemia; determinar el cumplimiento de los objetivos de aprendizaje de las asignaturas de acuerdo con la planificación implementada en la presencialidad remota de la DET desde la perspectiva del personal académico y del estudiantado y un último objetivo que fue conocer el apoyo dado por la gestión de la unidad académica y otras instancias universitarias para realizar los ajustes a las estrategias didácticas desde la presencialidad remota.

\section{MATERIALES Y MÉTODOS}

Con el fin de determinar las estrategias didácticas implementadas por el personal académico y el estudiantado desde la presencialidad remota en la División de Educación para el Trabajo en tiempos de pandemia, se considera que el enfoque cuantitativo responde a la intencionalidad y condiciones necesarias para lograr los objetivos propuestos desde un diseño no experimental. Esto por cuanto interesa describir las siguientes variables: 1) estrategias didácticas implementadas por el personal académico de la DET para dar continuidad al proceso educativo del estudiantado; 2) percepción del estudiantado en relación con las estrategias didácticas implementadas para la atención de la emergencia sanitaria; 3) cumplimiento de los objetivos de aprendizaje de las asignaturas de acuerdo con la planificación implementada en la presencialidad remota y 4) apoyo dado por la gestión de la unidad académica y otras instancias universitarias para realizar los ajustes a las estrategias didácticas desde la presencialidad remota.

El estudio se llevó a cabo con personal académico y el estudiantado de la DET del primer y segundo ciclo del año 2020. La muestra utilizada fue no probabilística de participantes voluntarios, en la cual para Hernández, Fernández y Baptista (2014) "la elección de los elementos no depende de la probabilidad, sino de causas relacionadas con las características de la investigación o los propósitos del investigador" (p. 176); de modo que el instrumental construido y aplicado mediante la plataforma "Instrumentos" de la Universidad Nacional, la cual se basa en la aplicación LimeSurvey ${ }^{\circledR}$, se hizo llegar a la totalidad de la población, no obstante, se consideró únicamente a quienes respondieron. Dado el tipo de muestra, se obtuvo la participación de 18 personas académicas ( 5 masculinas y 13 femeninas) y 65 personas estudiantes (50 femeninas y 15 masculinas) siendo la mayoría del Bachillerato en Orientación (96,92\% del total).

En cuanto a la técnica, se trabajó con la encuesta por cuanto permite de manera semiestructurada preparar reactivos cuantitativos y otros cualitativos. Al respecto, Creswell (2009) define la "encuesta como un diseño que provee un plan para efectuar una descripción numérica de tendencias, actitudes u opiniones de una población mediante el estudio de una muestra de ella" (p. 201). La selección de esta técnica obedece a la situación coyuntural provocada por la pandemia, por cuanto permite la recolección de información de manera sistemática en menos tiempo, obtener insumos puntuales del objeto de estudio, la escalabilidad de esta y la factibilidad del medio digital para ser distribuida.

Para desarrollar la técnica, se trabajó con el cuestionario semiestructurado como instrumento, el cual Hernández, Fernández y Baptista (2014) mencionan que es un "conjunto de preguntas respecto de una o más variables que se van a medir, por lo que debe ser congruente con el planteamiento del problema (p. 217)". Se seleccionó este instrumento dada escalabilidad y versatilidad que presenta, asimismo, al ser un estudio de carácter exploratorio es un primer acercamiento al objeto de estudio.

Este cuestionario fue sometido a un proceso de validación a juicio de expertos, el cual, de acuerdo con Escobar-Pérez y Cuervo-Martínez (2008) 
es un método de validación útil para verificar la fiabilidad de una investigación que se define como una opinión informada de personas con trayectoria en el tema, que son reconocidas por otros como expertos cualificados en éste, y que pueden dar información, evidencia, juicios y valoraciones. (p. 29)

Producto de esta consulta a dos expertos, uno del área de investigación educativa y otro de estadística, a partir de la valoración se obtuvieron insumos de mejora de forma y fondo vinculados ajustes para precisar de mejor manera la validación de la metodología del estudio, así como especificar elementos de forma para que quedasen más claros los reactivos.

De manera paralela al cuestionario, se contabilizaron las diferentes estrategias didácticas anotadas en los programas de estudio de los cursos del I ciclo y II ciclo 2020, esto permitió cuantificar más de 60 estrategias didácticas planificadas por el personal docente en el mes de marzo de 2020 y 45 propuestas para el II ciclo para dar continuidad al proceso académico desde la presencialidad remota a raíz de la emergencia sanitaria provocada por la COVID-19. Estas estrategias fueron unificadas en 9 grandes tipos siguiendo la propuesta de Díaz-Barriga y Hernández (2005).

La información recolectada se tabuló en el programa ofimático Microsoft Excel ${ }^{\circledR}$ donde se identificaron los elementos prioritarios según las variables para pasar al proceso de análisis, el cual se representó mediante tablas y figuras, realizando confrontaciones con la teoría.

En cuanto al contexto de la investigación, la División de Educación para el Trabajo (DET) es la unidad académica del Centro de Investigación y Docencia en Educación (CIDE) de la Universidad Nacional (UNA) que genera conocimientos y forma profesionales en Orientación, Administración Educativa, Gestión Educativa y Liderazgo, mediante procesos de educación formal, no formal y continua, integrando la docencia, investigación, extensión y producción académica para contribuir al desarrollo de la sociedad costarricense (DET, 2020).

\section{DISCUSIÓN DE RESULTADOS}

La investigación determinó que las estrategias didácticas del personal docente y estudiantado de la DET ante el tránsito hacia la presencialidad remota debido a la situación de emergencia, concretaron lo esperado de cualquier proceso educativo: el aprendizaje; en este caso desde la presencialidad remota; además se diversificaron las propuestas didácticas que se crearon para el estudiantado y la percepción de este fue que se lograron concretar los objetivos de aprendizaje de las distintas asignaturas del Bachillerato y Licenciatura en Orientación.

Para determinar lo anterior, la primera variable vinculada con "estrategias didácticas implementadas por el personal académico de la DET para dar continuidad al proceso educativo del estudiantado" encontró, luego de la revisión de los programas de las asignaturas (cursos) 60 estrategias didácticas implementadas por el personal académico en el I Ciclo, las cuales se detallan en la tabla 2. 
TABLA 2

Estrategias didácticas planificadas en el I Ciclo por el personal académico de la DET como producto de la modificación de acciones académicas durante la presencialidad remota

\begin{tabular}{|c|c|c|c|}
\hline Tipo de estrategia & \multicolumn{2}{|c|}{ Estrategias didácticas } & $\begin{array}{c}\text { Peso relativo } \\
\text { del tipo de estrategia }\end{array}$ \\
\hline $\begin{array}{l}\text { Activar o generar } \\
\text { conocimientos previos }\end{array}$ & $\begin{array}{l}\text { 1. Mapa conceptual } \\
\text { 2. Mapa mental } \\
\text { 3. Conferencia }\end{array}$ & $\begin{array}{l}\text { 4. Reflexiones } \\
\text { 5. Plenaria } \\
\text { 6. Sociodrama }\end{array}$ & 10 \\
\hline $\begin{array}{l}\text { Orientar y guiar sobre } \\
\text { los saberes disciplinares }\end{array}$ & $\begin{array}{l}\text { 7. Video tutorial } \\
\text { 8. Video magistral } \\
\text { 9. Guía de trabajo } \\
\text { 10. Análisis de películas } \\
\text { 11. Modelaje }\end{array}$ & $\begin{array}{l}\text { 12. Monigotes } \\
\text { 13. Video foro } \\
\text { 14. Manual } \\
\text { 15. Prácticas }\end{array}$ & 15 \\
\hline $\begin{array}{l}\text { Mejorar la codificación } \\
\text { elaborativa de la } \\
\text { información }\end{array}$ & $\begin{array}{l}\text { 16. Diapositivas } \\
\text { 17. Exposiciones } \\
\text { 18. Cuadro de doble entrada } \\
\text { 19. Infografías }\end{array}$ & $\begin{array}{l}\text { 20. Estudio de caso } \\
\text { 21. Video producción } \\
\text { 22. Cartel } \\
\text { 23. Collage }\end{array}$ & 13,34 \\
\hline $\begin{array}{l}\text { Organizar la información } \\
\text { nueva por aprender }\end{array}$ & $\begin{array}{l}\text { 24. Lecturas } \\
\text { 25. Análisis de noticias } \\
\text { 26. Bolsa de estrategias } \\
\text { 27. Esquemas } \\
\text { 28. Expedientes }\end{array}$ & $\begin{array}{l}\text { 29. Líneas de tiempo } \\
\text { 30. FODA } \\
\text { 31. Mapa familiar } \\
\text { 32. Portafolio }\end{array}$ & 15 \\
\hline $\begin{array}{l}\text { Promover el enlace entre } \\
\text { los conocimientos previos } \\
\text { y la nueva información }\end{array}$ & $\begin{array}{l}\text { 33. Proyecto } \\
\text { 34. Entrevista } \\
\text { 35. Exámenes } \\
\text { 36. Cuestionarios }\end{array}$ & $\begin{array}{l}\text { 37. Quiz } \\
\text { 38. Pruebas escritas } \\
\text { 39. Análisis de experiencias }\end{array}$ & 11,67 \\
\hline $\begin{array}{l}\text { Composición y aprendizaje } \\
\text { de textos }\end{array}$ & $\begin{array}{l}\text { 40. Ensayo } \\
\text { 41. Resumen ejecutivo } \\
\text { 42. Glosarios } \\
\text { 43. Síntesis } \\
\text { 44. Volantes }\end{array}$ & $\begin{array}{l}\text { 45. Comprobación de lectura } \\
\text { 46. Informe } \\
\text { 47. Procesamiento de textos } \\
\text { 48. Monografía } \\
\text { 49. Revista }\end{array}$ & 16,66 \\
\hline Autoaprendizaje & $\begin{array}{l}\text { 50. Investigaciones/indagación } \\
\text { 51. Tareas }\end{array}$ & $\begin{array}{l}\text { 52. Trabajo de campo } \\
\text { 53. Autobiografía }\end{array}$ & 6,66 \\
\hline Aprendizaje interactivo & $\begin{array}{l}\text { 54. Foro } \\
\text { 55. Debate } \\
\text { 56. Taller }\end{array}$ & $\begin{array}{l}\text { 57. Chats } \\
\text { 58. Conversatorio }\end{array}$ & 8,33 \\
\hline Aprendizaje colaborativo & 59. Artesanía de contextos & 60. Equipo de discusión & 3,34 \\
\hline
\end{tabular}

Fuente: Elaboración propia (2020).

De acuerdo con lo anterior, hubo una mayor cantidad de estrategias que respondieron a la clasificación de "Composición y aprendizaje de textos", "Organizar la información nueva por aprender" y "Orientar y guiar sobre los saberes disciplinares". Según Díaz-Barriga y Hernández (2005) estas "son aquellas estrategias destinadas a describir cómo se comprende y aprende de manera estratégica la información contenida en los textos académicos que habitualmente los estudiantes de diversos niveles educativos realizan" (p. 185), las estrategias de organizar la información de acuerdo con los mismos autores, se define como "proporcionan una adecuada organización de la información, mejora su significatividad lógica, y en consecuencia, hace más probable el aprendizaje significativo de los alumnos, genera construcción de conexiones internas" (p. 193) y las estrategias que se vinculan con orientar, para Díaz-Barriga y Hernández (2005) "son aquellos recursos que el profesor utiliza para guiar, orientar y ayudar a mantener la atención de los aprendices durante una sesión, discurso o texto" (p. 201). 
La información antes señalada, fue triangulada con los datos suministrados por el personal docente y el estudiantado en el instrumento aplicado, encontrándose una correspondencia en un $86,71 \%$ de lo anotado en la tabla 2; esto es, aunque en el programa del curso para el primer ciclo se indicó que se trabajaría con esa estrategia, en la práctica cuando se le consulta al estudiantado y a la persona académica se evidencia que no todas fueron implementadas, asimismo, cambia la ponderación, pues las estrategias de "Orientar y guiar sobre los saberes disciplinares" ocupan el primer lugar y las de "Composición y aprendizaje de textos" el segundo lugar de implementación. Como justificación se indica que no se logró hacer un ajuste en la presencialidad remota, a pesar de estar planificada con anterioridad para ello. En este punto es importante señalar que este personal docente no conocía la denominación de "presencialidad remota", pues un $66,67 \%$ del total indicó dicha aseveración. No obstante, a pesar de ello y tal como se explicó en los antecedentes, los procesos de incorporación de tecnología digital en la DET potenciaron la respuesta del personal docente para afrontar la crisis sanitaria provocada por el virus. Es así como, aunque mayormente no se conocía el término, el cuerpo académico de la DET brindó al estudiantado varias posibilidades didácticas con el fin de continuar con el aprendizaje durante el I Ciclo.

En cuanto al uso de estrategias didácticas planificadas e implementadas por el personal docente en el II Ciclo, luego de la revisión de los programas de las asignaturas (cursos) se detalla en la tabla 3 las que se planificaron.

TABLA 3

Estrategias didácticas planificadas en el II Ciclo por el personal académico de la DET como producto de la modificación de acciones académicas durante la presencialidad remota

\section{Tipo de estrategia}

Activar o generar conocimientos previos

Orientar y guiar sobre los saberes disciplinares

Mejorar la codificación elaborativa de la información

Organizar la información nueva por aprender

Promover el enlace entre los conocimientos previos y la nueva información

Composición y aprendizaje de textos

Autoaprendizaje

Aprendizaje colaborativo

\section{Estrategias didácticas}
1. Mapa conceptual
2. Rueda de ideas
5. Guías de trabajo
6. Guías de autoexploración:
8. Collage
9. Infografías
10. Egograma
14. Resumen
15. Cuadro comparativo
16. Cuadro de consistencia:
17. Cuadro de doble entrada:

21. Exámenes o pruebas escritas

23.Cuento

24. Ensayo

25. Lecturas y comprobaciones de lectura

29. Estudio de caso 30. Autobiografía

33.Taller

34. Debate

35. Círculo de diálogo

36. Mesa redonda

37. Panel de expertos

43. Foro

44. Trabajo grupal
22.Entrevista

6,6

\section{Película - cineforo}

4. Psicodrama

7. Video

11. Boletín

12. Póster

13. Muro virtual

18. Esquema

19. Flujograma

20. Portafolio

Peso relativo del tipo de estrategia utilizada

8,0

26. Informe

27. Glosario

28. Producción didáctica

31. Fichas - registros de aprendizaje

32. Investigaciones

38. Conversatorio

39. Exposición docente

40. Conferencia - charla

41. Blog

42. Wiki

45. Exposición de grupo 
Como puede observarse las estrategias de "aprendizaje interactivo" fueron las que mayormente se propusieron para los cursos del II Ciclo, seguidas de las de "aprendizaje colaborativo". De las estrategias más utilizadas están la exposición del docente y la exposición de los grupos, con un total de 35,6\% y $48,9 \%$ respectivamente. Ambas estrategias son las más comunes en la práctica docente; en este sentido Calderón (2015) plantea que la enseñanza grupal es la opción más utilizada después de la exposición del docente. Lo importante para esta autora, es ser eficiente en el uso de estas. Asimismo, en este grupo se puede observar que el taller, el círculo de diálogo, la mesa redonda y el foro son utilizados en algunos de los cursos; lo cual es valioso para el aprendizaje, especialmente porque permite el diálogo y una participación de las personas involucradas en el proceso de enseñanza-aprendizaje. Al respecto, DíazBarriga y Hernández (2005) indican que estas estrategias promueven el aprendizaje entre las personas participantes del proceso, de forma grupal o entre pares; lo cual es muy importante para el aprendizaje significativo.

Como tercer grupo de estrategias propuestas se encuentra la de "composición y aprendizaje de textos", con un total de un $75,6 \%$, las cuales describen cómo se aprende de manera estratégica, a partir de los diferentes textos (narrativos, expositivos, descriptivos, entre otros) utilizados en el proceso de aprendizaje (Díaz-Barriga y Hernández, 2005). Para el caso del estudio, la que obtuvo mayor porcentaje es la de lecturas y comprobaciones de lectura, con un $37,8 \%$.

La utilización de estrategias para el "autoaprendizaje", que promueven el aprendizaje autónomo y el aprender a aprender, obtuvo un 60\%. Se encuentran en este grupo, el estudio de caso, la autobiografía, las fichas de aprendizaje y las investigaciones. Al respecto, Chica Cañas (citada por Espinoza, 2017), indica que el aprendizaje autónomo impulsa la autogestión y apropiación del conocimiento y por ende se favorece el dominio de las habilidades de pensamiento de orden superior y los procesos metacognitivos de la persona.

El grupo de estrategias menos utilizadas fue el relacionado con "mejorar la codificación elaborativa de la información"; se puede constatar que el personal docente utiliza, el collage, las infografías, el egrograma, el boletín, el póster y mural. Se destaca el uso de la infografía, dentro de este grupo.

Ahora bien, el listado de estrategias recopilado en la tabla 2, se trianguló con la información brindada por el estudiantado y el mismo personal académico en el instrumento elaborado para tal fin, encontrándose una correspondencia de un 94,25\% a lo planificado en el programa del curso; situación diferente a lo acaecido en el primer ciclo de 2020. Al respecto, es importante señalar que para el segundo ciclo se tuvo la experiencia previa de cuatro meses desde la presencialidad remota, razón por la cual se cuenta con insumos para mejor toma de decisiones para la planificación didáctica.

De manera paralela se consultó al estudiantado las oportunidades de mejora que suponía la implementación de la estrategia didáctica implementada por el personal académico durante ambos ciclos, estas se indican en la tabla 4. 
TABLA 4

Oportunidades de mejora para el óptimo desarrollo de las estrategias didácticas planteadas por el estudiantado

Criterio
Porcentaje

\section{De acuerdo}

Logro de los objetivos del curso de acuerdo con la metodología del curso en la presencialidad remota.

Logro de los objetivos cuando hubo actividades grupales
32,31

63,08

64,62

41,54

Ni de acuerdo ni en desacuerdo

0

32.31

33.85

52.31

35,38

47,96

\section{En} desacuerdo

67,69

4,62

1,54

6,17

Fuente: Elaboración propia (2020).

Tal y como se muestra, el estudiantado requiere de una mayor inducción para la utilización de la tecnología digital, con el fin de cumplir a cabalidad las estrategias planteadas por la persona docente, pues un $67,69 \%$ no tuvo inducción para utilizar la plataforma tecnológica; situación que al contrastarlo con la información suministrada por el profesorado apenas un $16,67 \%$ de los participantes no contaba con capacitación para el uso de recursos digitales; ahora bien, un 52,31\% no está "ni de acuerdo ni en desacuerdo" en cómo se va desarrollar la asignatura en la presencialidad remota y en porcentajes entre un $30 \%$ y $35 \%$ en la realimentación, la claridad de las instrucciones y las actividades grupales desde esta modalidad. De este modo, podría inferirse que un desafío para el personal docente desde esta modalidad es generar un proceso de acompañamiento más cercano al estudiante, pues precisamente desde la condición remota es fundamental el "tender puentes" desde la mediación pedagógica docente para que esta sea oportuna, significativa y funcional.

Por otro lado, como complemento a lo propuesto por Jiménez y Robles (2016) cuando señalan que la estrategia didáctica también incluye el medio para su implementación, se consultó en el cuestionario del personal académico las aplicaciones digitales utilizadas para implementar las estrategias, las cuales se indican en la figura 1.

Figura 1. Aplicaciones digitales utilizadas por personal académico en los cursos de la DET en la presencialidad remota durante el primer y segundo ciclo.

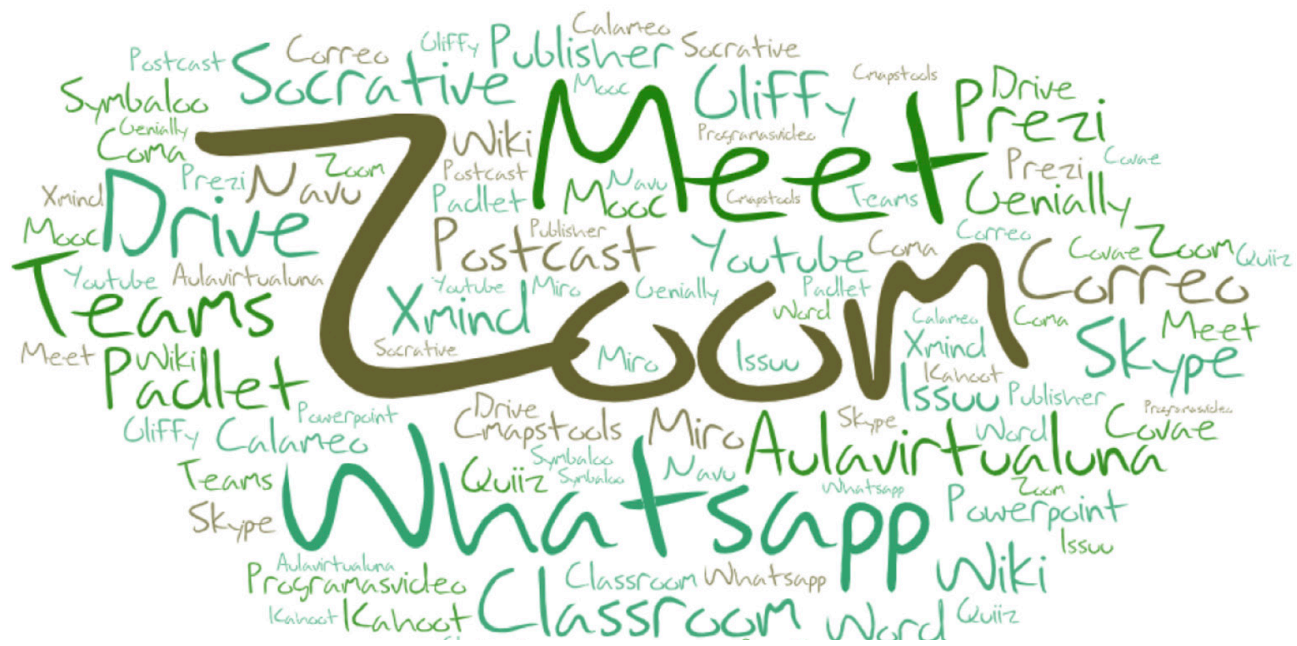

Fuente: Elaboración propia (2020). 
De acuerdo con la figura 1, la plataforma Zoom ${ }^{\oplus}$ y Google Meet ${ }^{\oplus}$ son las más mencionadas, precisamente porque permiten mantener un esquema ya conocido por el personal docente que es la lección "magistral", pero ahora desde un medio remoto llevando a cabo sesiones sincrónicas; también se mencionan el servicio de mensajería instantánea WhastApp ${ }^{\circledR}$ y la plataforma Microsoft Teams ${ }^{\circledR}$.

En lo que respecta a la segunda variable, percepción del estudiantado en relación con las estrategias didácticas implementadas para la atención de la emergencia sanitaria, en la tabla 5 , se muestran los resultados obtenidos.

TABLA 5

Percepción del estudiantado en relación con las estrategias implementadas durante la presencialidad remota (primer ciclo, 2020)

\begin{tabular}{|c|c|c|c|}
\hline \multirow[b]{2}{*}{ Criterio } & \multicolumn{3}{|c|}{ Porcentaje } \\
\hline & De acuerdo & $\begin{array}{l}\text { Ni de acuerdo } \\
\text { ni en desacuerdo }\end{array}$ & $\begin{array}{c}\text { En } \\
\text { desacuerdo }\end{array}$ \\
\hline $\begin{array}{l}\text { Cumplimiento del cronograma de actividades en el período de } \\
\text { presencialidad remota }\end{array}$ & 64,62 & 29,23 & 6,15 \\
\hline $\begin{array}{l}\text { Comunicación continua del personal académico acerca de lo pro- } \\
\text { gramado en el curso }\end{array}$ & 56,92 & 33,85 & 9,23 \\
\hline Cumplimiento de los esperado en el curso & 38,46 & 35,38 & 26,15 \\
\hline Se utilizó material complementario & 61,54 & 32,31 & 6,15 \\
\hline Diversidad de estrategias didácticas & 53,85 & 29,23 & 16,92 \\
\hline Vinculación de estrategias didácticas con los contenidos del curso & 86,15 & 13,85 & 0 \\
\hline Realización de sesiones sincrónicas & 92,31 & 7,69 & 0 \\
\hline Las sesiones sincrónicas fueron de provecho & 63,08 & 29,23 & 7,69 \\
\hline $\begin{array}{l}\text { Coherencia entre la evaluación de los aprendizajes } \\
\text { y la estrategia didáctica }\end{array}$ & 67,69 & 27,69 & 4,62 \\
\hline $\begin{array}{l}\text { Atención de consultas en el tiempo estipulado en el programa } \\
\text { del curso }\end{array}$ & 73,85 & 18,46 & 7,69 \\
\hline Seguimiento y/o acompañamiento de la persona docente & 64,62 & 30,77 & 4,62 \\
\hline
\end{tabular}

Fuente: Elaboración propia (2020).

Al observar la tabla 5, relacionada con la segunda variable en análisis, destacan los siguientes resultados. Un $64,62 \%$ del estudiantado señaló tener claridad de los cronogramas, sin embargo, una tercera parte indicó estar "ni de acuerdo ni en desacuerdo". Al respecto se puede señalar que en su mayoría resultó positivo, pero dado que las mismas indicaciones emanadas por las autoridades de la institución dejaban vacíos en la consideración de las modificaciones en calendario universitario, es comprensible la existencia de un alto porcentaje que no alcanzó a estar "de acuerdo". Aunque es frecuente utilizar medios digitales que respalden los recordatorios para las actividades o pendientes de trabajos, más de la mitad señaló que se ofrecieron. Sin embargo, deja entreabiertos los motivos por los cuales cerca de un $40 \%$ no manifestó estar "de acuerdo". Cuando se valora el criterio acerca de las expectativas del curso, los resultados están distribuidos de una forma casi equitativa, levemente destaca estar "de acuerdo" con un $38,46 \%$, resultando negativo en términos de motivación para dar continuidad al proceso de enseñanza y aprendizaje. Respecto a si se contaba con material complementario para el desarrollo del curso 61,54\% indicó estar "de acuerdo", mientras que un 32,31\% "ni de acuerdo ni en desacuerdo" el porcentaje es bajo cuando se valora el criterio y que se califica "en desacuerdo", este se ubica en un 6,15\%. Al tratar el criterio de variedad de actividades didácticas se observa que poco más de la mitad señaló estar "de acuerdo", con un 53,85\%, en este caso "ni de acuerdo ni en desacuerdo" alcanza un 29,23\%. En términos generales se tiene manifiesto que la categoría "ni de acuerdo ni en desacuerdo" se mantiene 
cercana a un tercio en la mayoría de los criterios de toda la tabla. Al abordar el criterio de si las actividades implementadas por la persona docente estaban relacionadas con los temas del curso, el porcentaje alcanzado por la categoría "de acuerdo" alcanza el segundo valor más alto de la tabla, corresponde a un $86,15 \%$, destaca que se presenta valor cero por ciento "en desacuerdo". El mayormente valorado como "de acuerdo" corresponde a la realización de sesiones sincrónicas con un 92,31\%, este corresponde al porcentaje más alto de la tabla, y el restante porcentaje se ubicó en "ni de acuerdo ni en desacuerdo". Sin embargo, al tratar de valorar qué tan provechosas fueron las sesiones se obtiene un $63,08 \%$, mientras que "en desacuerdo" representó un 7,69\%.

En lo referente al criterio de evaluación y su correspondencia con la metodología del curso se mantienen muy similares al criterio anterior, un 67,69\% señaló estar "de acuerdo", un 27,69\% "ni de acuerdo ni en desacuerdo" y solo un 4,62\% indicó estar "en desacuerdo". Al tratar el criterio de si se atendían las inquietudes en el tiempo estipulado más de dos terceras partes señaló estar "de acuerdo" lo que representa un $73,85 \%$, mientras que un $18,46 \%$ indicaron estar "ni de acuerdo ni en desacuerdo" y únicamente un $7,69 \%$ "en desacuerdo". Acerca del seguimiento a lo largo de todas las actividades desde la presencialidad remota, el porcentaje se acerca mucho a lo señalado en los recordatorios de actividades y pendientes, un 64,62\% indicó estar "de acuerdo", un 30,77\% señaló estar "ni de acuerdo ni en desacuerdo", y estar "en desacuerdo" un 4,62\%.

En virtud de los resultados descritos, el estudiantado está de acuerdo en continuar con la presencialidad remota, pues señalan que prefieren una combinación de sesiones sincrónicas y asincrónicas desde su lugar de residencia, siendo la virtualización de cursos una opción poco preferida, lo que se muestra en la figura 2.

Figura 2. Modalidad sugerida por el estudiantado para continuar con la presencialidad remota en la División de Educación para el Trabajo.

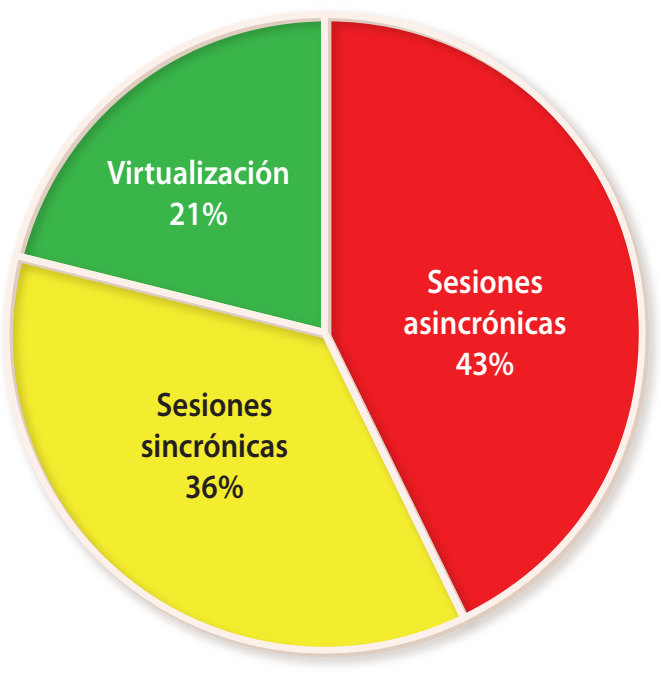

Fuente: Elaboración propia (2020).

De acuerdo con la figura 2, acerca de la modalidad preferida por el estudiantado para continuar con la presencialidad en la División de Educación para el Trabajo, se obtuvo con mayor porcentaje las clases asincrónicas alcanzando un 43\%, seguido de clases sincrónicas con un 36\% y en tercer lugar la virtualización con un $21 \%$. Estos resultados evidencian que las estrategias didácticas utilizadas en la DET han tenido aceptación y pertinencia dentro de los procesos de aprendizaje del estudiantado, principalmente 
cuando se ven reflejados de igual manera en las recomendaciones del estudiantado sobre su afinidad a las mismas, por ejemplo, señalan que es importante "Dinamismo y aprovechamiento de los recursos digitales para la presentación de trabajos", así como "en cuanto a actividades recomiendo utilizar mayor cantidad de juegos digitales, murales interactivos, debates, entre otras que sean realmente participativas y permitan a su vez, evaluar los aspectos necesarios". Lo anterior refuerza la propuesta de mantener las estrategias valoradas una vez que se regrese a la presencialidad de las aulas en la actividad pedagógica; esto se ve reforzado por Bertogna, del Castillo, Soto y Cecchi (s.f.) cuando afirman que la modalidad asincrónica

fomenta que los estudiantes y profesores pueden seguir cursos y cooperar con estudiantes y profesores de la universidad sin ir físicamente allí, soportados por las TIC's y el e-learning (...) permitiendo lograr continuidad de las clases teóricas/prácticas, lo que permitirá al alumno asimilar contenidos del mismo modo en que lo haría a través de la modalidad b-learning y/o presencial. (p. 10)

De acuerdo con esto, el esfuerzo realizado por el personal docente de la DET en respuesta al cambio de presencialidad remota en la UNA ha generado, entonces, una percepción de aceptación por parte del estudiantado para que la modalidad pueda continuar, situación que lleva a las instancias que toman decisiones a valorar aportes como este para las acciones a seguir en el corto plazo.

Por su lado, en relación con la variable de cumplimiento de los objetivos de aprendizaje de las asignaturas de acuerdo con la planificación implementada en la presencialidad remota, en la tabla 6 se presenta la información suministrada por el personal docente.

TABLA 6

Opinión del personal docente en relación con el cumplimiento de los objetivos de aprendizaje de las asignaturas de acuerdo con la planificación implementada en la presencialidad remota

\begin{tabular}{|c|c|c|c|c|c|}
\hline \multirow[b]{2}{*}{ Criterio } & \multicolumn{5}{|c|}{ Porcentaje } \\
\hline & $\begin{array}{l}\text { Muy de } \\
\text { acuerdo }\end{array}$ & $\begin{array}{l}\text { De } \\
\text { acuerdo }\end{array}$ & $\begin{array}{l}\text { Ni de acuerdo } \\
\text { ni en desacuerdo }\end{array}$ & $\begin{array}{c}\text { En } \\
\text { desacuerdo }\end{array}$ & NS/NR \\
\hline $\begin{array}{l}\text { La participación del estudiantado, para el cum- } \\
\text { plimiento de los objetivos del curso, en la moda- } \\
\text { lidad de presencialidad remota fue mayor que en } \\
\text { la modalidad presencial }\end{array}$ & 16,67 & 11,11 & 55,56 & 11,11 & 5,55 \\
\hline $\begin{array}{l}\text { Las estrategias didácticas implementadas en la } \\
\text { presencialidad remota permitieron el cumpli- } \\
\text { miento y desarrollo de los saberes del curso }\end{array}$ & 44,44 & 38,89 & 11,11 & 0 & 5,55 \\
\hline $\begin{array}{l}\text { El material didáctico digital promovió el cumpli- } \\
\text { miento de los objetivos del curso }\end{array}$ & 44,44 & 33,33 & 16,67 & 0 & 5,55 \\
\hline $\begin{array}{l}\text { El uso de tecnología promovió la comprensión di- } \\
\text { dáctica del curso }\end{array}$ & 55,56 & 16,67 & 11,11 & 0 & 5,55 \\
\hline $\begin{array}{l}\text { La modalidad de presencialidad remota permite } \\
\text { el cumplimiento de los objetivos del curso }\end{array}$ & 44,44 & 33,33 & 11,11 & 5,55 & 5,55 \\
\hline
\end{tabular}

Fuente: Elaboración propia (2020).

Al consultar al personal académico acerca de si la participación del estudiantado fue mayor que en la presencialidad, el mayor porcentaje corresponde a $55,56 \%$ y se ubicó en la categoría "Ni de acuerdo ni en desacuerdo", por lo que no parece que se viera afectada esta condición por el cambio de modalidad. Por otra parte, bajo esta modalidad el desarrollo de saberes parece que se ve favorecido, ya que entre las categorías "muy de acuerdo" y "de acuerdo" alcanzan casi el 83,29\%. De igual forma más del 77\% señaló que hubo un aprovechamiento del material didáctico entre las categorías "muy de acuerdo" y "de acuerdo". Por último, al realizar la sumatoria de las opciones "Muy de acuerdo" y "De acuerdo" el 77,77\% 
del personal académico participante del estudio considera que la presencialidad remota permite el cumplimiento de los objetivos del curso, es decir, no solo hay una alta aceptación a la presencialidad remota, sino, es viable para continuar implementándose. Esto evidencia un reto para futuros procesos investigativos con el fin de conocer las razones del restante porcentaje de participantes del porqué la presencialidad remota no cumple con los objetivos programados.

Al analizar los resultados de esta variable se considera importante destacar algunas de las recomendaciones que se desprenden del estudiantado y que se ajustan a los criterios señalados, por ejemplo una de las recomendaciones sugiere "ser un poco más comprensivos con lo de la conectividad", factor que sin duda alguna es determinante para comprobar la participación, señalan además que se pueden "hacer ejercicios para que pongan las cámaras", ya que la conectividad no es un factor suficiente para establecer un grado de participación. Respecto a motivar la participación del estudiantado en los cursos resultan importantes estas dos recomendaciones: "clases sincrónicas con un tiempo corto y provechoso" y "equilibrio entre lo sincrónico y asincrónico". Para Rivera (2020), el abordaje de estrategias didácticas apoyadas por medio de las tecnologías digitales es importante por cuanto

implica concebir los procesos de enseñanza y aprendizaje desde nuevas ópticas, una situación que implica nuevos retos, roles y habilidades para los alumnos y por supuesto también para los docentes: el alumnado se convierte en el constructor de su propio aprendizaje y los docentes tienen ahora la responsabilidad de guiar al alumno en este proceso, pero con una visión, formación y competencias de carácter tecnificado para que el aprendizaje sea lo más natural para estas nuevas generaciones de alumnos. (párr. 2)

De acuerdo con lo anterior y para la misma variable, el estudiantado señaló que la presencialidad remota favoreció el desarrollo de los cursos, por cuanto más de la mitad del estudiantado indicó que fue fortalecido, mientras que un 32,31\% señaló estar "ni de acuerdo ni en desacuerdo". Ambos porcentajes se ven alterados levemente cuando se hace referencia al alcance de objetivos en las actividades grupales, esto porque cerca del $48 \%$ señaló estar "de acuerdo" y un 35,38\% alcanzó a estar "ni de acuerdo ni en desacuerdo". Para ambas consultas se observa que un porcentaje (bajo pero significativo), señaló estar "en desacuerdo", respecto al fortalecimiento en el desarrollo de contenidos, un $10,77 \%$ y respecto al alcance de objetivos grupales sube ligeramente a un $16,92 \%$.

Estos resultados están acompañados también de elementos a considerar que se desprenden de la modalidad por ejemplo, algunos comentarios del estudiantado son: "a veces nos cargan tanto de manera que tardamos de 5 a 6 horas para cumplir con las actividades y cabe agregar que una gran cantidad de actividades no aseguran el aprendizaje", otro aspecto que podría interpretarse como afectado, es el tiempo en las sesiones sincrónicas, ya que señalan "en primer lugar, considerar que, según la VVD (Vicerrectoría de Vida Estudiantil) una clase deja de ser pedagógica después de dos horas en modalidad virtual, sin embargo, se entiende que por la modalidad de los cursos de la escuela deben cumplir con las horas de clase, aun así, las clases de exposiciones y con dinámicas magistrales son excesivamente agotadoras para el estudiantado...", lo cual deja claro que podría existir, además, una interpretación errónea del uso que debe darse a cada recurso para alcanzar adecuadamente los objetivos cuando son llevado a la práctica.

Aunado a lo anterior, se sugiere que exista un mayor acompañamiento de la persona docente en relación con las estrategias que se implementan, o bien, cuando las áreas temáticas son complejas en su abordaje, así se indica que "cuando implementen actividades innovadoras consideren brindar una explicación básica sobre estas. Y brinden explicaciones o guías con instrucciones claras". Al respecto, es fundamental en la entrega de la docencia, "las estrategias didácticas deben ser debidamente seleccionadas de acuerdo con los objetivos (...), no deben usarse estrategias, o actividades que el estudiante no comprenda. Muchas veces el uso de una técnica compleja o desconocida obstaculiza el aprendizaje" (Picado, 2014, p. 132). Se espera de la persona docente que se capacite para el uso de las diferentes herramientas 
y plataformas utilizadas en la presencialidad remota, así se solicita "más capacitaciones para académicos y estudiantes para el uso de las diferentes plataformas", igualmente se aproveche la gran variedad de recursos, así se recomienda "utilizar mayor cantidad de juegos digitales, murales interactivos, debates, entre otras que sean realmente participativas y permitan a su vez, evaluar los aspectos necesarios".

En relación con el último objetivo propuesto, vinculado con la cuarta variable, apoyo dado por la gestión de la unidad académica y otras instancias universitarias para dar realizar los ajustes a las estrategias didácticas desde la presencialidad remota, en la tabla 7, se muestran los datos suministrados por el personal docente.

TABLA 7

Apoyo brindado por las instancias institucionales, según el personal docente, para los ajustes a las estrategias didácticas en la presencialidad remota

\begin{tabular}{lccccc}
\multicolumn{1}{c}{ Nombre de la instancia } & \multicolumn{5}{c}{ Apoyo recibido } \\
& Muy bueno & Bueno & Regular & Malo & Muy malo \\
Rectoría & 11,11 & 38,89 & 44,44 & 0 & 5,56 \\
Vicerrectoría de Docencia & 38,89 & 27,78 & 27,78 & 0 & 5,56 \\
CONSACA & 16,67 & 27,78 & 50 & 5,56 & 0 \\
Decanato o Vicedecanato & 16,67 & 55,56 & 27,78 & 0 & 0 \\
Gestión de la Unidad Académica (DET) & 61,11 & 33,33 & 5,56 & 0 & 0 \\
Coordinación de Nivel & 38,89 & 33,33 & 16,67 & 5,56 & 5,56 \\
\hline
\end{tabular}

En relación con el apoyo recibido por las diferentes instancias institucionales, el personal indica que el apoyo recibido por la Gestión de la División de Educación para el trabajo, en el transitar didáctico de la presencialidad a la presencialidad remota, ha sido muy bueno $(61,11 \%)$, seguido de la coordinación del nivel (de la misma Unidad Académica) y de la Vicerrectoría de Docencia (38,89\%), asimismo, indican que el apoyo del Decanato y Vicedecanato del CIDE ha sido bueno (55,56\%). Dichos resultados cobran relevancia en tanto se reconoce la labor de las instancias cercanas al personal docente. Se evidencia que la gestión, representada en la dirección y subdirección, atiende lo que establece el Estatuto orgánico de la UNA, en los artículos 73 y 75, en cuanto a las tareas que competen desde el puesto, en relación con la función de la persona en la dirección de la Unidad Académica se indica que debe "facilitar la comunicación asertiva y la coordinación al interior y exterior de la unidad" (Estatuto orgánico, art.73, inciso e, p. 54), además, se indica para el caso de la persona que ocupa el cargo de subdirección "atender y gestionar los asuntos estudiantiles en la unidad o en otras instancias universitarias, según corresponda, para favorecer el desarrollo académico, personal y social". (art.75, inciso d, p. 55).

Los resultados obtenidos podrían ser una buena oportunidad para continuar con la mejora de los procesos educativos, especialmente si se considera que las instancias respectivas brindan los apoyos necesarios para el logro de objetivos.

Por su parte el colectivo estudiantil, indica no haber recibido apoyo por parte de las instancias universitarias en el tránsito a la presencialidad remota cuando desarrollaron lo propuesto en los programas de los cursos; aspecto que debe considerarse para mejorar los canales de comunicación y el acercamiento al estudiantado, ya que el proceso de aprender implica más que la transmisión de contenidos, requiere tomar en cuenta las necesidades particulares del estudiantado. Esto es de particular importancia por cuanto señalan Hodges, Moore, Lockee, Trust y Bond (2020) que en la presencialidad remota "los equipos de apoyo al profesorado desempeñan un papel fundamental en las experiencias de aprendizaje de los estudiantes al ayudar a desarrollar experiencias de aprendizaje cara a cara o en línea" (párr. 35). La información contenida en la tabla 8 indica lo mencionado por el estudiantado participante. 
TABLA 8

Apoyo brindado por las instancias, según el estudiantado, para desarrollar las estrategias didácticas en la presencialidad remota

\begin{tabular}{|c|c|c|c|c|c|c|}
\hline \multirow[b]{2}{*}{ Instancias } & \multicolumn{6}{|c|}{ Porcentaje } \\
\hline & $\begin{array}{l}\text { Muy de } \\
\text { acuerdo }\end{array}$ & $\begin{array}{c}\text { De } \\
\text { acuerdo }\end{array}$ & $\begin{array}{c}\text { Ni de acuerdo } \\
\text { ni en desacuerdo }\end{array}$ & $\begin{array}{c}\text { En } \\
\text { desacuerdo }\end{array}$ & $\begin{array}{c}\text { Muy en } \\
\text { desacuerdo }\end{array}$ & NS/NR \\
\hline $\begin{array}{l}\text { Contó con apoyo efectivo de la } \\
\text { Oficina de Atención Estudiantil } \\
\text { u otros servicios como el } \\
\text { Laboratorio de informática del } \\
\text { CIDE. }\end{array}$ & 5,56 & 5,56 & 27,78 & 11,11 & 22,22 & 27,78 \\
\hline $\begin{array}{l}\text { Contó con apoyo de algunas } \\
\text { instancias de la Universidad } \\
\text { Nacional para adecuar el mate- } \\
\text { rial didáctico requerido en los } \\
\text { cursos. }\end{array}$ & 5,56 & 5,56 & 22,22 & 11,11 & 27,78 & 27,78 \\
\hline
\end{tabular}

Fuente: Elaboración propia (2020).

Por último, en lo que respecta a la búsqueda de información y de apoyos, la persona docente indicó, según se establece en la tabla 9, que se prefirió buscar el apoyo entre el mismo personal de la unidad. Las personas que buscaron el apoyo en otras instancias lo solicitaron en términos de la asistencia a capacitaciones ofrecidas por la Vicerrectoría de Docencia; al personal en el área de informática; a la búsqueda de videos ubicados en el sitio web oficial de la UNA, entre otros. No obstante, se indica que también hubo personas que manifestaron considerar otros horarios que permitan tener acceso a las capacitaciones ofrecidas por la UNA.

TABLA 9

Apoyo solicitado por el personal docente para realizar los ajustes a las estrategias didácticas en la presencialidad remota

\begin{tabular}{|c|c|c|c|}
\hline \multirow{2}{*}{ Criterio } & \multicolumn{3}{|c|}{ Porcentaje } \\
\hline & Si & No & NS / NR \\
\hline $\begin{array}{l}\text { ¿Solicitó apoyo a otros funcionarios académicos para realizar los ajustes demandados } \\
\text { en el plan de contingencia para la transición hacia la presencialidad remota? }\end{array}$ & 61,11 & 38,89 & 0 \\
\hline $\begin{array}{l}\text { Recurrió al apoyo académico brindado por la Vicerrectoría de Docencia (Unidad de } \\
\text { Evaluación, Mejoramiento e Integración Tecnológica en la Docencia) para la implemen- } \\
\text { tación desde la presencialidad remota. }\end{array}$ & 38,89 & 61,11 & 0 \\
\hline
\end{tabular}

Fuente: Elaboración propia (2020).

Para el caso del apoyo que ha recibido el estudiantado, indican que este especialmente fue ofrecido por el personal docente (52,31\%) y su grupo de pares (50,77\%), seguido de la Vicerrectoría de Vida Estudiantil $(12,31 \%)$ y la Dirección y Subdirección (10,77\%). Nuevamente recobra importancia el papel de la persona docente en el proceso de enseñanza-aprendizaje, especialmente porque esta, debe:

facilitar y orientar el proceso educativo, ayudar al educando a construir su propio conocimiento, promover un ambiente de respeto y autoconfianza que dé oportunidad para el aprendizaje, valorar los errores e identificar los estilos de aprendizaje del estudiantado (...) Los docentes son los promotores de un adecuado ambiente dentro del aula, en donde cada espacio constituye un microcosmos en el que los estudiantes comparten elementos culturales, lenguajes, códigos y saberes específicos. El docente, como uno de los protagonistas del proceso educativo, está llamado a proporcionar las oportunidades para fomentar las relaciones interpersonales, la comunicación efectiva y el intercambio de vida, de manera que en las aulas se propicie una verdadera formación integral (UNA, Modelo pedagógico, 2007, p. 8). 
Lo anteriormente expuesto deja de manifiesto que, para el personal docente participante del estudio, el proceso de enseñanza-aprendizaje es más que la trasmisión de conocimiento; es necesario atender otros aspectos de la persona, en su integralidad. Cada persona tiene una serie de características que están permeadas por un contexto específico, al cual se suma una situación de pandemia.

\section{CONCLUSIONES}

La investigación determinó que las estrategias didácticas implementadas por el personal académico para con el estudiantado de la DET, ante el tránsito hacia la presencialidad remota debido a la situación de emergencia producida por el virus responsable de la COVID-19 fueron oportunas para producir el efecto deseado (el aprendizaje desde la presencialidad remota) en el contexto vivido, esto por cuanto el profesorado reorganizó el proceso, planteo diversidad de estrategias, generó empatía con la tecnología digital, saco ventaja del medio remoto, entre otros. Al respecto, se cumple con lo señalado por Hodges, Moore, Lockee, Trust y Bond (2020) cuando afirman que la "enseñanza remota de emergencia", o para el contexto UNA, presencialidad remota, "requiere que los profesores tomen más control del proceso de diseño, desarrollo e implementación del curso" (párr. 35).

En cuanto a las estrategias didácticas implementadas por el personal académico de la DET en la presencialidad remota se logró evidenciar que se diversificaron, además, implementaron diversos recursos tecnológicos para cada una de ellas; aspecto que responde a una característica propia de la presencialidad remota, término desconocido por la mayoría del personal antes de la pandemia producida por el virus responsable de la COVID-19, no obstante, dicha diversificación implica el acompañamiento al estudiantado y la necesidad de capacitación de ambas partes. En relación con esto, de acuerdo con la clasificación de estrategias de Díaz-Barriga y Hernández (2005) el personal de la DET implementó mayormente estrategias didácticas orientadas a la "Composición y aprendizaje de textos", "Organizar la información nueva por aprender", "Orientar y guiar sobre los saberes disciplinares", "aprendizaje interactivo" y "aprendizaje colaborativo". Al respecto, Díaz-Barriga y Hernández (2005) indican que estas estrategias son "de tipo coinstruccional dado que pueden aplicarse de manera continua para indicar a los alumnos en qué conceptos o ideas focalizar los procesos de atención y codificación (p. 187)", aspecto que puede deducirse fundamental para la presencialidad remota, siendo, entonces, un aporte a las ciencias de la educación en contextos de emergencia como el que provocó la pandemia de la COVID-19.

Por su lado, en cuanto a la percepción del estudiantado en relación con las estrategias didácticas implementadas para la atención de la emergencia sanitaria, se evidenció aspectos positivos en relación con este aspecto, destacándose la diversificación de las mismas y la vinculación del uso de tecnología digital como complemento para el logro de lo establecido en los cursos y buscado mediante las estrategias, del mismo modo, sugieren seguir implementando la modalidad de sesión asincrónica, combinada con sesiones sincrónicas.

Asimismo, en cuanto al cumplimiento de los objetivos de aprendizaje de las asignaturas de acuerdo con la planificación implementada en la presencialidad remota, se denota que se da un aprovechamiento de las estrategias implementadas, se logra el cumplimiento de objetivos y abordaje de contenidos, aunque se requiere oportunidades de mejora. En este aspecto no hay claridad en el personal docente, en cuanto al aumento del grado de participación del colectivo estudiantil, así como en la mejora del rendimiento académico. Se destaca la demanda de acompañamiento especialmente cuando se implementan estrategias innovadoras. Un reto por determinar es vincular los resultados de esta investigación con los datos cuantitativos de aprobación registrados por el Departamento de Registro de la UNA, que al momento de ejecutarse este proceso aún no están disponibles. 
En relación con la última variable vinculada con el apoyo dado por la gestión de la unidad académica y otras instancias universitarias para realizar los ajustes a las estrategias didácticas desde la presencialidad remota, se enfatiza en el que brinda la gestión y las instancias del CIDE, hacia el personal docente y el del personal docente y la gestión hacia el estudiantado.

En suma, la respuesta del equipo académico y estudiantil de la DET ante el tránsito hacia la presencialidad remota respondió a los principios de conveniencia, flexibilidad, funcionalidad y significatividad requeridos para esta opción de aprendizaje remoto, planteando estrategias de aprendizaje que respondieron al cumplimiento de los objetivos establecidos en las diferentes asignaturas que se ofertaron durante el primer ciclo de 2020 y la percepción de lo que se espera para el segundo ciclo, de este modo se puede inferir que el aprendizaje remoto en la DET, de acuerdo con el Ilinois State Board of Education (2020) fue "inclusivo y equitativo para todos los estudiantes, independientemente de su edad, ubicación, antecedentes y recursos disponibles" (p. 7), dado que las diversidad de estrategias didácticas implementadas potenció el logro del hecho educativo.

Por último, este estudio es una primera aproximación para que se desarrollen más investigaciones con el fin de determinar la pertinencia curricular, de acceso tecnológico y pedagógica de los procesos educativos desde la presencialidad remota, del mismo modo, es necesario determinar la pertinencia y/o efectividad de la presencialidad remota pero desde el aprendizaje, haciendo no solo comparaciones con la presencialidad tradicional sino también desde la significatividad y/o funcionalidad para el estudiantado; del mismo modo es perentorio conocer cómo se desarrolla esa interacción en la presencialidad remota desde la vinculación del profesorado-estudiantado, estudiantado-estudiantado, estudiantado-contenidos, estudiantado-recursos didácticos, entre otros. Contrario a otros estudios y/o afirmaciones de entidades internacionales (Elacqua y Schady, 2020), esta investigación demuestra que se logró continuar de manera oportuna con el proceso educativo del estudiantado de las ofertas académicas de la DET y que se tiene una percepción de éxito entre los participantes, no obstante, lo que es cierto, tal como afirma Elacqua y Schady (2020) es necesario "repensar nuestros sistemas educativos e impulsar reformas sistémicas sentarán las bases para revertir el rumbo actual y avanzar en la eficiencia, calidad y equidad educacional en la región (párr. 13).

\section{REFERENCIAS}

Alexander, B. (2020). Coronavirus and higher education resources. Recuperado de https://bryanalexander.org/coronavirus/coronavirus-and-higher-education-resources/

Bertogna, L., Del Castillo, R., Soto, H. y Cecchi, L. (s.f.). Clases Sincrónicas Virtuales en la Enseñanza a Distancia: una implementación a bajo costo. Recuperado de http://sedici.unlp.edu.ar/bitstream/ handle/10915/19102/Documento_completo.pdf?sequence=1

Calderón, K. (2015). La didáctica: concepciones y aplicaciones. San José, C.R: EUNED.

Colom, A., Sureda, J., Salinas, J. (1988). Tecnología y medios educativos. Barcelona: Cincel-Kapelusz.

Creswell, J. (2009). Research Design. Qualitative, Quantitative and Mixed Methods Approaches. United States: Sage.

Díaz-Barriga, F. y Hernández, G. (2005). Estrategias docentes para un aprendizaje significativo. Una interpretación constructivista. México: Mc Graw Hill Interamericana.

División de Educación para el Trabajo [DET] (2020). ¿Quiénes somos?. Recuperado de https://www.cidetrabajo.una.ac.cr/index.php/quienes-somos 
Elacqua, G. y Schady, N. (2020). La educación ante el Covid-19 en América Latina: Retos y alternativas de política. Banco Interamericano de Desarrollo. Recuperado de https://blogs.iadb.org/educacion/ es/retosyalternativasdepoliticaeducativa/

Espinoza, E. (2017). El aprendizaje en estudiantes universitarios. Cienfuegos, Cuba: Editorial Universo Sur. Recuperado de https://elibro.net.una.remotexs.co/es/ereader/unacr/71777? page=24.

Fëdorov, A. (2004). ¿Cómo programar un curso? Guía para evaluar y autoevaluar el programa de curso. Cartago: Editorial Tecnológica de Costa Rica.

Good, T. y Brophy, J. (1986). School effects. En: Wittrock, M. (Ed.). Handbook of research on teaching. New York: MacMillan.

Guevara, C. (2017). La estrategia didáctica y su uso dentro del proceso de enseñanza y aprendizaje en el contexto de las bibliotecas escolares. E-Ciencias de la Información. 7 (1). 1-22. http://dx.doi. org/10.15517/eci.v7i1.27241

Hernández, R., Fernández, C., Baptista, P. (2014). Metodología de la Investigación. Sexta Edición. México: Mc Graw Hill.

Hodges, C.; Moore, S.; Lockee, B.; Trust, T. y Bond, A. (2020). The Difference Between Emergency Remote Teaching and Online Learning. En Educause Review. Recuperado de https://er.educause. edu/articles/2020/3/the-difference-between-emergency-remote-teaching-and-online-learning

Ilinois State Board of Education (2020). Recomendaciones de aprendizaje remote. Recuperado de https://www.isbe.net/Documents/RL-Recommendations-Spanish.pdf

Jiménez, A. y Robles, F. (2016). Las estrategias didácticas y su papel en el desarrollo del proceso de enseñanza aprendizaje. Revista EDUCATICONCIENCIA. 9 (10). 106-113. Recuperado de http://192.100.162.123:8080/bitstream/123456789/1439/1/Las\%20estrategias\%20didacticas\%20 y\%20su\%20papel\%20en\%20el\%20desarrollo\%20del\%20proceso\%20de\%20ense\%C3\%B1anza \%20aprendizaje.pdf

Picado, F. (2014). Didáctica general. Una perspectiva integradora. San José, Costa Rica: EUNED.

Rivera, E. (2020). La tecnología como herramienta de aprendizaje. Recuperado de https://www.cuc.ac.cr/ userfiles/files/BLOG/Blog\%2027\%20de\%20marzo\%252c\%20La\%20tecnolog\%C3\%ADa\%20 como\%20herramienta\%20de\%20aprendizaje.pdf

Tijo, S. (2020). Enseñanza remota de emergencia en ingeniería civil: lecciones aprendidas. Encuentro Internacional de Educación en Ingeniería. Recuperado de https://acofipapers.org/index.php/eiei/ article/view/781

UNESCO (2020). Sistematización de respuesta de los sistemas educativos de América Latina a la crisis de la COVID-19. Recuperado de https://www.siteal.iiep.unesco.org/respuestas_educativas_covid_19

Universidad Nacional. (2007). Modelo Pedagógico. Heredia: Universidad Nacional. Recuperado de http://www.documentos.una.ac.cr/bitstream/handle/unadocs/3084/Modelo\%20Pedagogico. pdf?sequence $=1$ \&isAllowed $=\mathrm{y}$

Universidad Nacional. (2015). Estatuto orgánico. Heredia: Universidad Nacional.

Vicerrectoría de Docencia (2020a). Orientaciones metodológicas y evaluativas para apoyar la adaptación de los cursos presenciales a sesiones con apoyo tecnológico. Heredia: Universidad Nacional. Recuperado de http://www.documentos.una.ac.cr/bitstream/handle/unadocs/11533/De-lapresencialidad-al-trabajo-academico-remoto-2020.pdf?sequence=1\&isAllowed=y

Vicerrectoría de Docencia (2020b). Encuesta posibilidades de uso de tecnologías del estudiantado. Heredia:Universidad Nacional. Recuperado de http://www.docencia.una.ac.cr/resultado-de-la-es cuesta-por-estudiante/caracteristica-tecnologicas/resultado-utilizado-herramientas-tecnologicas 